NIST Special Publication 260-183

\title{
SRM 1967a: High-Purity Platinum Thermoelement
}

K. M. Garrity

D. C. Ripple

W. L. Tew

This publication is available free of charge from:

http://dx.doi.org/10.6028/NIST.SP.260-183

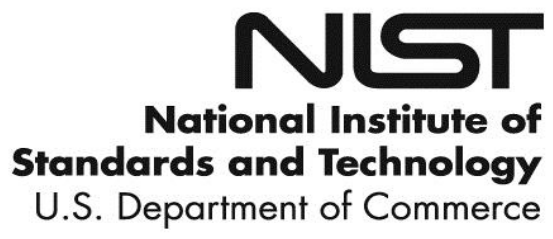


NIST Special Publication 260-183

\title{
SRM 1967a: High-Purity Platinum Thermoelement
}

\author{
K. M. Garrity \\ W. L. Tew \\ Sensor Science Division \\ Physical Measurement Laboratory \\ Dean C. Ripple \\ Biomolecular Measurement Division \\ Material Measurement Laboratory
}

This publication is available free of charge from:

http://dx.doi.org/10.6028/NIST.SP.260-183

June 2015

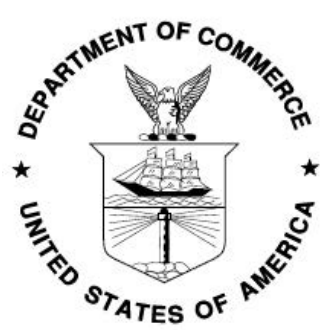

U.S. Department of Commerce

Penny Pritzker, Secretary

National Institute of Standards and Technology Willie May, Acting Under Secretary of Commerce for Standards and Technology and Acting Director 
Certain commercial entities, equipment, or materials may be identified in this document in order to describe an experimental procedure or concept adequately. Such identification is not intended to imply recommendation or endorsement by the National Institute of Standards and Technology, nor is it intended to imply that the entities, materials, or equipment are necessarily the best available for the purpose.

National Institute of Standards and Technology Special Publication 260-183 Natl. Inst. Stand. Technol. Spec. Publ. 260-183, 29 pages (June 2015)

CODEN: NSPUE2

This publication is available free of charge from: http://dx.doi.org/10.6028/NIST.SP.260-183 


\begin{abstract}
Consisting of a $1 \mathrm{~m}$ long piece of $0.5 \mathrm{~mm}$ diameter platinum wire, SRM 1967a (Pt67a) meets the requirements for a thermoelectric reference material for temperatures from $-196{ }^{\circ} \mathrm{C}$ up to approximately $1700{ }^{\circ} \mathrm{C}$. We have tested the thermoelectric emf of four SRM 1967a cuts versus five cuts from the prior reference standard SRM 1967 (Pt67) lot. The tests indicate that SRM 1967a differs from SRM 1967 by less than $1.5 \mu \mathrm{V}$ throughout its temperature range. The thermoelectric inhomogeneity of SRM 1967a is comparable to or smaller than that of the original SRM 1967. The certified results provide the basis for treating the new (Pt67a) and old (Pt67) lots of Pt wire as thermoelectrically equivalent. The new material is suitable as a standard thermoelectric material that replicates the average of the Pt67 response to within an expanded $(k=2)$ uncertainty of $\pm 0.5 \mu \mathrm{V}$ up to $400{ }^{\circ} \mathrm{C}$ and rising to $1.5 \mu \mathrm{V}$ at $1700{ }^{\circ} \mathrm{C}$.
\end{abstract}

Keywords: platinum; Standard Reference Material; thermocouple; thermoelectric material; thermal emf; 


\section{Table of Contents}

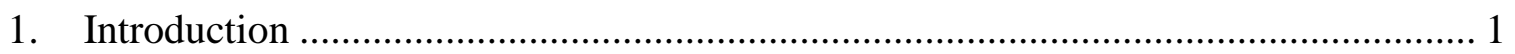

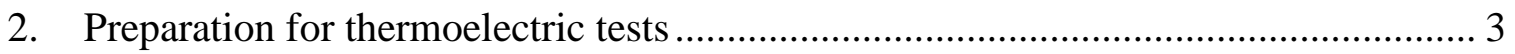

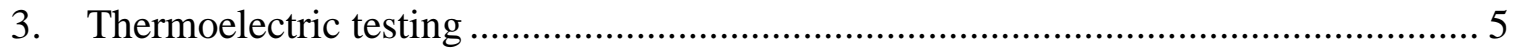

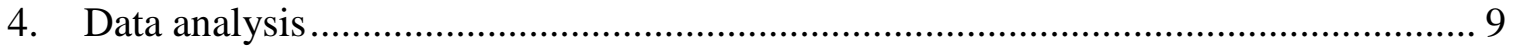

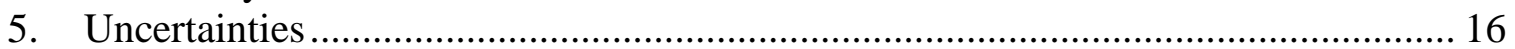

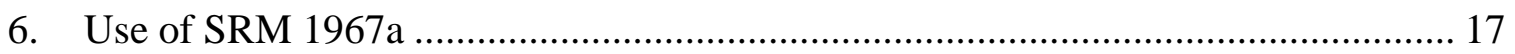

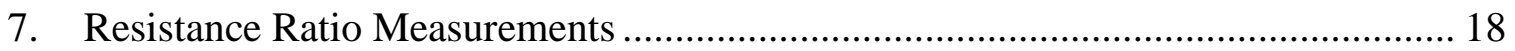

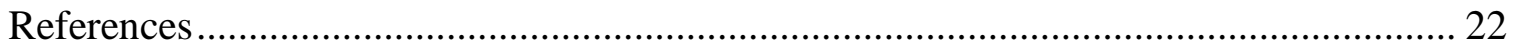

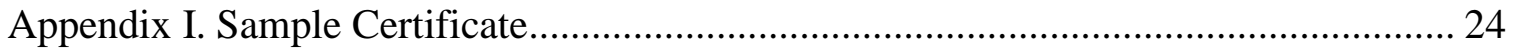

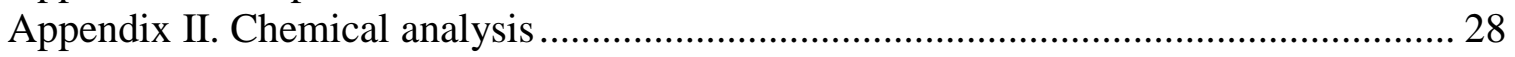




\section{Introduction}

Thermocouples, composed of two dissimilar metals (i.e. 'thermoelements') joined at one end, have numerous applications as one of the most common industrial temperature sensors. When the joined end is placed in the thermal zone to be measured, and the unjoined ends are maintained at a reference temperature, a thermocouple generates a net thermal electromotive force (emf) across the wires. In the case where no electrical current flows through the thermocouple, the emf is equivalent to the voltage measured across the thermocouple.

Practical thermocouple thermometry involves the use of many different combinations of dissimilar metals with standardized emf values specified as functions of temperature [1]. The use of a single pure metal thermoelement to serve as a common reference, or 'thermoelectric standard', for all standardized thermocouple materials enables the emf standardization to be established with the greatest degree of reproducibility from one lot of material to another. Platinum has long served as the best choice for a thermoelectric standard for several important reasons. Platinum resists oxidation over a broad temperature range, is readily purified, and has a melting point $\left(1768^{\circ} \mathrm{C}\right)$ high enough to cover most of the range useful for thermocouple measurements.

An ideal platinum thermoelectric standard would have no impurities. Such a standard would be repeatable from cut to cut and have a well-defined chemical state. In practice impurities are unavoidable, but when the concentrations are low their influence is tolerable and a sufficiently high-purity thermoelectric standard conveys the necessary degree of reproducibility for standardization. Another advantage, which is not as obvious, is that a highly pure wire cut will remain thermoelectrically more homogeneous along its length after exposure to heat during annealing or use. This is important since an inhomogeneous distribution of impurities (i.e. 'inhomogeneity') along the length of a thermoelement will alter its thermoelectric emf. Furthermore, the presence of a temperature gradient in a region of a thermoelement with otherwise homogeneous impurities will over time induce an inhomogeneous distribution of those impurities within the thermoelement [1].

Standard Reference Material ${ }^{\mathrm{TM}}\left(\mathrm{SRM}^{\mathrm{TM}}\right)$ 1967a is a high-purity (approximately $99.999 \%$ by mass) platinum wire, $0.51 \mathrm{~mm}$ in diameter and $1 \mathrm{~m}$ long, suitable for use as a standard reference thermoelement for calibrations of base and noble metal thermocouple materials in the temperature range $-196{ }^{\circ} \mathrm{C}$ to approximately $1700{ }^{\circ} \mathrm{C}$. Standardized emf values versus temperature, based on the International Temperature Scale of 1990 (ITS-90) [2], are given in NIST Monograph 175 [3].

The common designation of 'Pt67' is synonymous with SRM 1967; similarly, SRM 1967a may be referred to as 'Pt67a'. The thermoelectric values obtained for Pt67a as a sampled lot of material are certified by NIST relative to Pt67 based on NIST comparisons described in this report. Within a specified uncertainty, we find that the new Pt67a wire is thermoelectrically equivalent to the old Pt67 wire and no correction is necessary. The 
degree of equivalence is described in section 4 and the relevant uncertainties are discussed in section 5. For a given sample of SRM 1967a, it may be slightly thermoelectrically positive or negative relative to a given sample of SRM 1967. In certain cases, therefore, we recommend that results obtained by a user for a specific sample of Pt67a be corrected to the values that would have been obtained using a specific sample of Pt67 wire as a reference. The conventional practice for making such a correction is described in section 6 .

SRM 1967a is highly pure, but it has not been prepared with as much care as the original lot of Pt67, due to economic constraints. While the two lots of material are thermoelectrically indistinguishable, other types of measurements that may readily reveal significant differences are possible. Examples of such measurements are the resistance ratios presented in section 7 . Given the limited amount of samples examined, however, those data are not included as certified values. In the Appendix, we discuss non-certified values for the chemical impurity concentrations found in a single sample of SRM 1967a.

SRM 1967 replaced the former standard, Pt-27, which was used from 1922 until January 1973. The high-purity platinum standard reference material SRM 680 was issued in 1967 by the NBS Office of Standard Reference Materials [5] and provided the basis for Pt67. More specifically, Pt67 was a selected, highly homogeneous portion of the former chemical composition standard, the SRM 680. That SRM was also in wire form, but was provided in short lengths only and with certified impurity concentrations. The portion of SRM 680 which had been set aside for thermoelectric use was later recertified in 1977 as SRM 1967 and disseminated in 1 meter lengths. The historical development of Pt67, its characterization, and properties are described in NBS Special Publication 260-56 [6].

A set of comprehensive studies on the thermoelectric effects of impurities on platinum [7],[8],[9] confirms Cochrane's [8] hypothesis that,

"...the effect of an individual impurity on the emf of platinum was essentially linear, and that the total effect of impurities was simply additive (or subtractive in the case of gold) of the effects of the individual impurities".

The effect of any atomic impurity does depend on the chemical state of the impurity; for example, silicon in solution has a large effect, but silicon in the form of silicon dioxide is largely inert. For high-quality platinum wire, iron is often the impurity with the greatest impact on the thermal emf, but this element's contribution to EMF is likewise sensitive to the oxidation state.

A platinum thermoelectric standard has several established uses:

1. A reference standard for the calibration of platinum working standards. In practice, it is often cost effective to compare a second lot of platinum wire to SRM 1967a, and use this second lot as the working standard. For users performing frequent calibrations, this practice reduces the need for a large number of SRM 1967a cuts, and reduces the risk of contaminating the SRM 1967a thermoelement with extensive use. 
2. The prediction of thermocouple output. If two thermoelements are both tested against platinum, then the results may be combined to predict the thermoelectric output of a thermocouple composed of the two tested thermoelements. For example, a manufacturer may test multiple lots of the positive leg of a type $\mathrm{K}$ thermocouple (KP) against platinum, and multiple lots of the negative leg (KN) as well. Knowing the responses of the individual lots allows tuning of the thermocouple response by appropriate selection of KP and $\mathrm{KN}$ lots.

3. The Standardization of single thermoelement response. ASTM and IEC standards for thermocouple emf versus temperature tables do not specify that single thermoelements (e.g., KP) are interchangeable, but many manufacturers do guarantee that the response of single thermoelements vs. Pt will meet certain specifications. This guarantee ensures interchangeability: the combination of any $\mathrm{KP}$ spool of wire with any $\mathrm{KN}$ spool of wire will meet the thermocouple specification for a type $\mathrm{K}$ thermocouple.

4. A common baseline for reporting the thermoelectric response of new materials. Measuring and reporting new materials against platinum traceable to SRM 1967a gives results that are readily combined with the thermoelectric response of other materials.

SRM 1967a meets the requirements for a thermoelectric reference material for temperatures from $-196{ }^{\circ} \mathrm{C}$ up to approximately $1700^{\circ} \mathrm{C}$. Above $1100{ }^{\circ} \mathrm{C}$, the results are based on extrapolation, and our knowledge of the emf variability of the lot is limited. On the other hand, measurements above $1100{ }^{\circ} \mathrm{C}$ are subject to larger uncertainties and the possible lot variability is still much less than the likely other uncertainty components. Below $50 \mathrm{~K}$, the properties of platinum become sensitive to the composition and level of impurities, and SRM 1967a is not recommended.

\section{Preparation for thermoelectric tests}

The wire used for SRM 1967a consisted of $32 \mathrm{~m}$ of $0.51 \mathrm{~mm}$ diameter platinum wire. The wire was obtained from a commercial precious metals refiner as a single continuous draw of wire on a single spool [10]. We cut 32 consecutive, $1 \mathrm{~m}$ lengths of wire to form the set of SRM 1967a cuts. Each cut was packaged in a virgin polyethylene bag. We took considerable care to keep the wire free of contamination, by wearing latex gloves and using Teflon-coated tools for all steps except the wire cutting. The carbide-steel wire cutter was designated for platinum use only. A circular Teflon jig helped us cut the coiled wire into $1 \mathrm{~m}$ lengths without straightening the wire. Four of the cuts, (\#1,\#10,\#20, and \#30) evenly spaced through the lot, were used as the Pt67a test samples. We also took a set of four, $1 \mathrm{~m}$ long cuts from a spool of the original stock for SRM 1967, which formed the test samples for the original Pt67. Ideally, these cuts would be equally spaced throughout the SRM 1967 lot, but only this one spool remained of the available stock, so these wire cuts (\#8 to \#11) where all contiguous. These four Pt67 samples were labeled A, B, C, and D and the four Pt67a cuts were labeled E, F, G, and H. In later tests, a ninth 
sample was added, this was cut \#7 from our original spool of SRM 1967, labeled Pt67-7, which had undergone extensive annealing during previous use at NIST. We designate this sample as ' $Z$ '. The specific cut numbers and letter designations for each of these nine thermoelements are shown in Table 1.

Each wire was electrically annealed by the same procedure used for the certification of the SRM 1967 [6]. To ensure that the ends of the wire stayed clean and also reached the full anneal temperature, we welded on short, platinum extension wires to each sample, which were cut off after the annealing process. The wire was annealed for 10 minutes at $1200{ }^{\circ} \mathrm{C}$, cooled over a period of $1 \mathrm{~min}$ to $750{ }^{\circ} \mathrm{C}$; held at $750{ }^{\circ} \mathrm{C}$ for 60 minutes, and then cooled to room temperature over a period of $1 \mathrm{~min}$.

Single-bore alumina insulators of nominal $99.7 \%$ purity were used to hold and insulate the platinum wires. Prior to use, the insulators were baked in air at $1100{ }^{\circ} \mathrm{C}$ for one hour using a commercial 3-zone furnace. We used a platinum pull wire, welded to the end of each test wire, to draw the test wire into the insulator. Coated fiberglass sleeving insulated the platinum wire at the room-temperature end. To form a reference junction, we soldered on a length of copper wire (thermocouple grade, type TP). In order to minimize emf differences between the cuts of platinum, all of the copper wires were cut from the same spool. Finally, all eight of the test samples were welded together with a hydrogen torch to form a common measuring junction. Figure 1 shows the completed junction plus assembly test bundle for the low temperature and three-zone furnace measurements (see section 3). This test bundle was later separated into two bundles for the measurements that took place in a second furnace (see section 3.3).

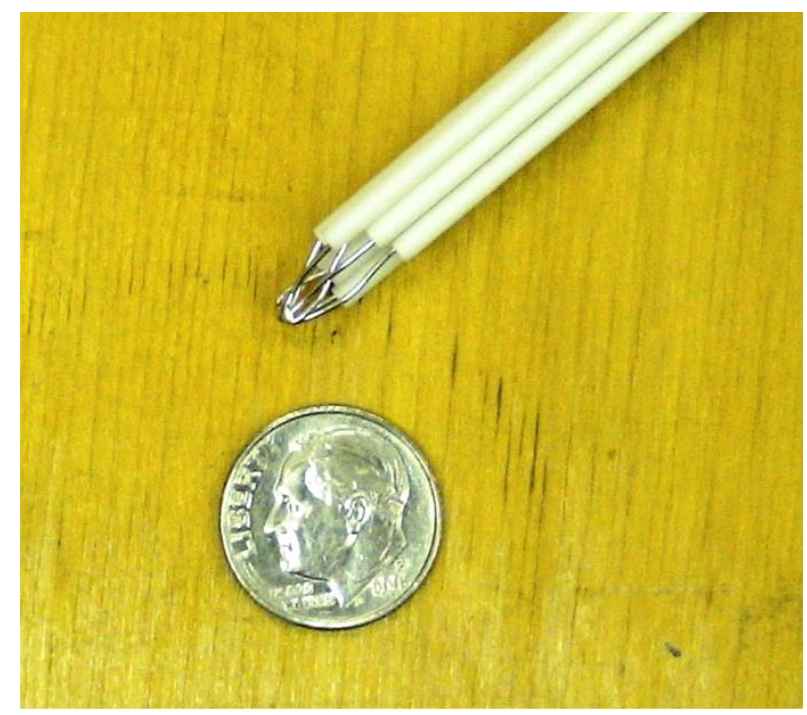

Fig. 1. Common measuring junction of the test bundle of eight platinum thermoelements as configured for use in the three-zone furnace tests. 


\section{Thermoelectric testing}

High temperature testing was accomplished using two different tube furnaces and different thermoelement test bundle configurations. Initial tests were conducted using a commercial three-zone tube furnace ('3-Zone') and later tests were carried out using a custom-built silicon carbide $(\mathrm{SiC})$ tube furnace. A type $\mathrm{S}$ reference thermocouple was used to determine the temperature in the region of the test bundle junction. Contrary to the standard practice in our laboratory for the calibration of thermocouples, we did not weld a reference thermocouple into the common junction of the test bundles. We reasoned that, on one hand, the emf of SRM 1967a vs. SRM 1967 varies very little with temperature, so an error in knowing the bundle temperature as large as $20{ }^{\circ} \mathrm{C}$ would produce only a negligible error in the emf function. On the other hand, incorporation of rhodium into the measuring junction from welding on a type $S$ thermocouple could result in a high sensitivity to the temperature gradients imposed on the measuring junction by the furnace. Since the three-zone furnace had non-uniformities $\lesssim 2{ }^{\circ} \mathrm{C}$, we could readily use a type $S$ thermocouple located adjacent to the platinum thermoelement bundle as the reference thermometer. Although the $\mathrm{SiC}$ furnace is not as uniform along its length as the three-zone furnace, the type $S$ temperature reference was once again not welded to the bundle.

The measurement system consisted of a junction box, a scanner equipped with low thermal-emf relays, and an $81 / 2$ digit multimeter (DMM) with auto-calibration features. An ice-point $\left(0^{\circ} \mathrm{C}\right)$ reference junction was employed for each $\mathrm{Pt}$ thermoelement, allowing all-copper lead wires to connect the individual thermoelectric circuits to the gold-plated copper scanner input terminals.

Methods of data acquisition followed those established for high-accuracy measurements of gold versus platinum thermocouples [11]. Here, we give only a brief summary. Stray thermal emf values from the copper wiring and scanner are corrected by shorting all channels of the junction box and measuring each of the data channels against a channel that remained shorted at all times, which we term the reference short. The average difference of each channel from the reference short is taken as a correction for that channel. Drift in the zero reading of the DMM was corrected by measuring the reference short at the front and back of each set of emf measurements. These corrections were applied to the low temperature measurements and the three-zone furnace and SiC furnace data.

The $0{ }^{\circ} \mathrm{C}$ to $1100{ }^{\circ} \mathrm{C}$ test data was a combination of separate comparisons made in two separate furnaces with different wire-bundle combinations in multiple experimental runs. Table 1 shows how the nine thermoelements were distributed in each of these runs. The tested wire combinations were chosen with two goals in mind:

- Measure the emf of SRM 1967a versus SRM 1967 in multiple combinations of cuts, and

- Measure all wires with respect to one reference wire.

By measuring all wires with respect to one common wire, it is possible to determine the emf of any one wire versus any other wire using no more than two pair combinations. 
Table 1. The distribution of Pt67 and Pt67a sample thermoelement combinations in the three main experimental furnace runs for $t>0{ }^{\circ} \mathrm{C}$. Each cell which is filled in with a color and text represents a thermoelement combination which was measured in that run. All pair combinations that are represented by blank cells were determined by the subtraction of two single-pair EMF measurements. (There is normal pair-wise redundancy reflected across the diagonal of the table as in a two-dimensional indexed matrix)

\begin{tabular}{|c|c|c|c|c|c|c|c|c|c|c|}
\hline & Letter & $\begin{array}{ll}67-8 \\
\end{array}$ & & & 67-11 & & & $67 a-10$ & $67 a-20$ & $67 a-30$ \\
\hline Cut\# & $\begin{array}{l}\text { Letter } \\
\text { Designations }\end{array}$ & A & & & & & & & & \\
\hline $67-8$ & $\mathbf{A}$ & & 3-Zone & 3-Zone & 3-Zone & SiC-1/SiC-2 & 3-Zone & 3-Zone & 3-Zone & 3-Zone \\
\hline $67-9$ & B & 3-Zone & & & & SiC-2 & & & & \\
\hline $67-10$ & C & 3-Zone & & & & SiC-2 & & & & \\
\hline $67-11$ & D & 3-Zone & & & & SiC-1/SiC-2 & & & & \\
\hline $67-7$ & $\mathbf{Z}$ & SiC-1/SiC-2 & SiC-2 & $\mathrm{SiC}-2$ & SiC-1/SiC-2 & & SiC-1 & SiC-2 & SiC-2 & SiC-1 \\
\hline 67a-1 & $\mathbf{E}$ & 3-Zone & & & & SiC-1 & & & & \\
\hline $67 a-10$ & $\mathbf{F}$ & 3-Zone & & & & SiC-2 & & & & \\
\hline $67 a-20$ & G & 3-Zone & & & & SiC-2 & & & & \\
\hline $67 a-30$ & $\mathbf{H}$ & 3-Zone & & & & SiC-1 & & & & \\
\hline
\end{tabular}

\subsection{Three-zone furnace tests}

For the first series (circa 2008) of tests in the range $0{ }^{\circ} \mathrm{C}$ to $1100{ }^{\circ} \mathrm{C}$, we used a commercial three-zone tube furnace (' 3 -Zone' in Table 1). The furnace active control zones were segmented with heaters in lengths of $152 \mathrm{~mm}, 610 \mathrm{~mm}$, and $152 \mathrm{~mm}$. The test bundle and type $\mathrm{S}$ reference thermocouple were inserted into an alumina protection tube with junctions centered in the uniform zone. The relative emf between various pairs of platinum wires (as discussed below) was tested at room temperature, $200{ }^{\circ} \mathrm{C}, 450{ }^{\circ} \mathrm{C}$, $700{ }^{\circ} \mathrm{C}, 900{ }^{\circ} \mathrm{C}$ and $1100{ }^{\circ} \mathrm{C}$. Three different runs were conducted, measuring six pairs of wires for each run. These measurements were taken relative to Pt67-8 ('A').

Initial measurements in this furnace revealed spurious voltage signals at temperatures of $900{ }^{\circ} \mathrm{C}$ and above. The problem disappeared when the furnace was briefly turned off and was greatly reduced when the alumina insulators were lifted off of the bottom of the alumina protecting tube. This evidence, together with the observation that the severity of the problem increases rapidly at high temperature, suggests that the furnace heater current couples into the thermoelements through electrical leakage in the alumina insulators.

We attempted to obtain data on a rapid cooling (approximately $2 \mathrm{~h}$ ) of the furnace with no power. In this mode, the ends of the furnace cool faster than the center, and large thermal non-uniformities developed. The emf data showed anomalous behavior at times when the non-uniformities were largest, and we rejected this mode of furnace operation.

We obtained the best data by stabilizing the furnace temperature at each temperature, turning off the furnace, and acquiring data before large thermal non-uniformities could develop. This method was used for all of the three-zone furnace data reported here. 


\subsection{Low Temperature Thermoelectric Testing}

Measurements at temperatures below $0{ }^{\circ} \mathrm{C}$ followed procedures very similar to those described above, except for the method used to control the test bundle temperature. For tests at $-90{ }^{\circ} \mathrm{C}$, the bundle was inserted into a closed-end glass tube, and the tube was inserted into a stirred alcohol bath. A calibrated platinum resistance thermometer measured the temperature. For tests at $-196{ }^{\circ} \mathrm{C}$, we inserted the glass tube and test bundle into a dewar filled with liquid nitrogen. The thermoelements were inserted $41 \mathrm{~cm}$ into the baths. They were allowed at least 10 minutes to equilibrate before any data was taken. Three different runs consisting of three sets of wire combinations were measured at both temperatures. At least three sets of data were taken for each run and averaged to obtain one measurement for each wire pair per run. As with the three-zone furnace the data was taken with Pt67-8 as the reference wire.

\subsection{Silicon-carbide furnace testing}

In March 2012 new comparison data was taken between Pt67a and Pt67 thermoelements in a $\mathrm{SiC}$ tube furnace [12] (see Figure 2). The reference Pt wire was an extensively annealed cut of Pt67 known as Pt67-7 (' $Z$ '). Prior to data taking, Pt67-7 was annealed overnight at $450{ }^{\circ} \mathrm{C}$. The thermocouple used as the data taking temperature reference was a type $\mathrm{S}$ thermocouple labelled SC-98-Pt. Its measuring junction was located next to the thermoelement bundle's common measuring junction; however, it was not electrically connected to the bundle. Data was taken on March 7, 2012 (SiC-1 data) and April 17, 2012 (SiC-2 data). The two data runs included different thermoelements.

The SiC-1 assembly was a bundle of 5 test wires including Pt67a-1, Pt67a-30, Pt67-8, and Pt67-11 (E, H, A, and D). The SiC-2 assembly included test wires Pt67a-10, Pt67a20, Pt67-8, Pt67-9, Pt67-10, and Pt67-11 (F, G, A, B, C, and D). Data was taken relative to the reference wire Pt67-7 (' $Z$ ' as the negative leg of each pair of wires) in both assemblies. Prior to making measurements a four wire short was applied to the rear input of the DMM. Then the known offset for rear terminal measurements of the DMM were subtracted. Upon completion of the offset adjustment the four-wire short was removed and the leads from the scanner were reattached. Then the internal gain and offset parameters were calibrated for all dc voltage ranges such that the DMM would remain linear and self-consistent with respect to its internal voltage reference. After preparation of the DMM, copper wire shorts were put on each channel of the junction box that was used for measurements. Channel 1 had a permanent short on it (which took account of the non-zero emf generated by the DMM) throughout the measurement cycle. Five sets of short data were taken both before and after the comparison data was taken. The average difference of each channel from the reference short is taken as a short correction for that channel. Only channel 1 was shorted during the data acquisition.

Several sets of data were taken at room temperature. Then the temperature of the furnace was increased to approximately $1064^{\circ} \mathrm{C}$, stabilized, and multiple sets of data were taken. Data was taken at approximately the fixed-point temperatures of gold, silver, aluminum, zinc, and tin. 
When the furnace had stabilized at $965^{\circ} \mathrm{C}$, data was taken at various immersion depths to look at homogeneity along the lengths of the wires. Normal immersion depth was $38 \mathrm{~cm}$. Data was taken at the immersion depths of $38 \mathrm{~cm}, 40.5 \mathrm{~cm}, 38 \mathrm{~cm}, 35.5 \mathrm{~cm}$, and $38 \mathrm{~cm}$. The observed differences between the upper and lower limits of immersion were within the limits of reproducibility achieved at the nominal immersion depth of $38 \mathrm{~cm}$ as indicated by repeating those measurements between the excursions from the upper to lower immersion depth.

Upon completion of the immersion measurements the furnace temperature was reduced to $810{ }^{\circ} \mathrm{C}$, stabilized, and data was taken. The same procedure was repeated at $660{ }^{\circ} \mathrm{C}$, $422{ }^{\circ} \mathrm{C}$, and $230{ }^{\circ} \mathrm{C}$. Both data runs, $\mathrm{SiC}-1$ and $\mathrm{SiC}-2$, followed the same procedure.

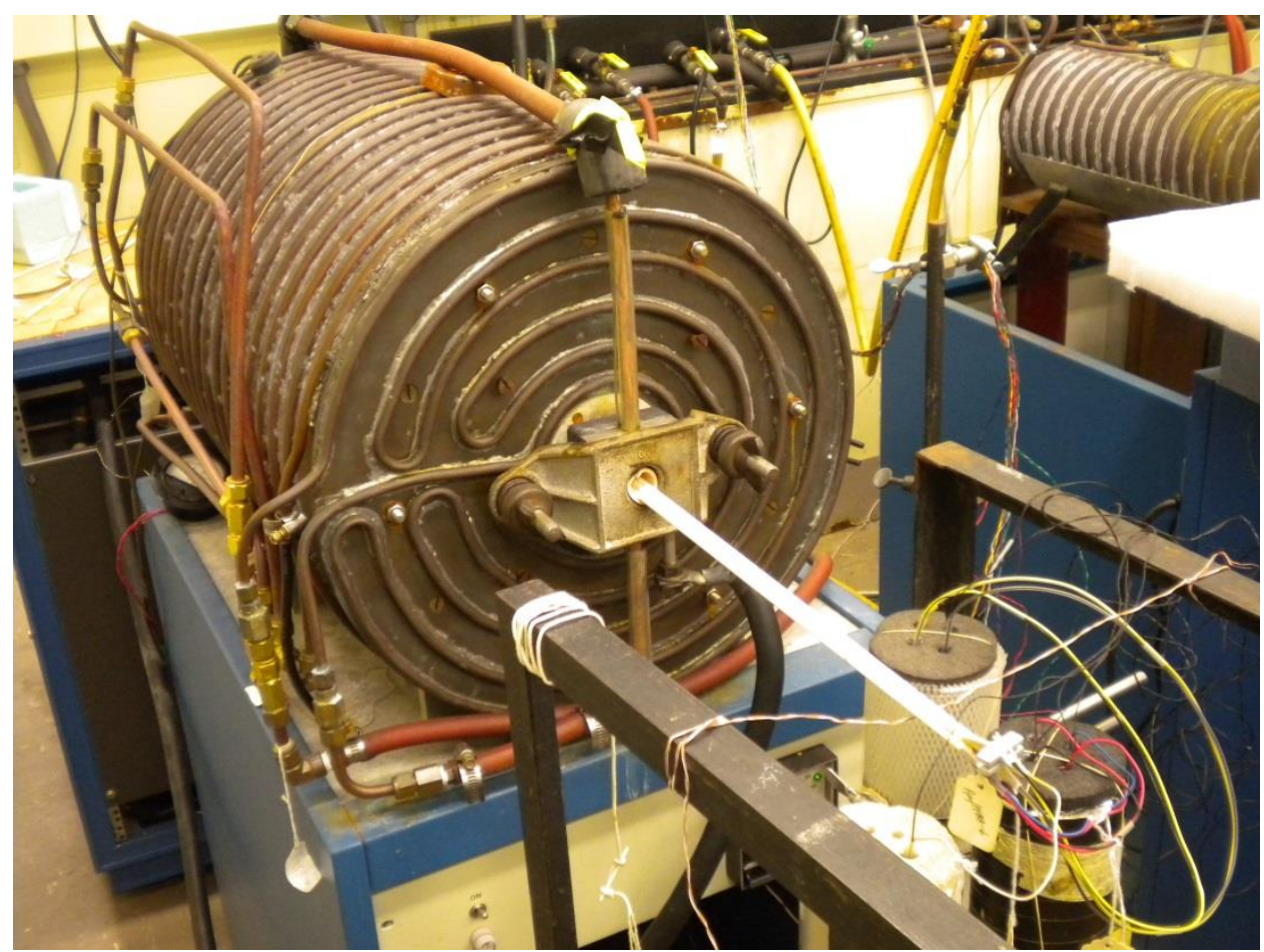

Figure 2. The SiC furnace during testing of a bundle of Pt67 and Pt67a thermoelements. 


\section{Data analysis}

From routine calibrations in the NIST Thermocouple Calibration Laboratory, we knew that a quadratic function adequately models the differences in emf versus temperature of any two lots of high purity platinum above $0{ }^{\circ} \mathrm{C}$. We had less experience at temperatures below $0{ }^{\circ} \mathrm{C}$ and did not wish to constrain the fit. The functional form chosen for the absolute emf of wire $i$ as a function of temperature was:

$$
\begin{aligned}
E_{i}(t) & =a_{i} t+b_{i} t^{2} & & t \geq 0{ }^{\circ} \mathrm{C} \\
& =c_{i} & & t=-90{ }^{\circ} \mathrm{C} \\
& =d_{i} & & t=-196{ }^{\circ} \mathrm{C},
\end{aligned}
$$

where $t$ is the temperature on the International Temperature Scale of 1990 (ITS-90) [2].

For a measurement of the emf of thermoelement $i$ versus thermoelement $j$, the emf difference is:

$$
\Delta E_{i j}(t)=E_{i}(t)-E_{j}(t)
$$

Note that we cannot determine the absolute emf or Seebeck coefficient of any thermoelement - we can only measure differences between the emf generated by each pair of thermoelements connected as a thermocouple. As a result, the parameters in Eq. 1 for the full set of tested thermoelements cannot be uniquely identified. There are nine thermoelements under study here with four free parameters each. However, for thermocouples made from twenty unique combinations of Pt67a with Pt67 thermoelements, the observable coefficients are $a_{i}-a_{j}, b_{i}-b_{j}, c_{i}-c_{j}$, and $d_{i^{-}} d_{j}$ for $i=\mathrm{Z}, \mathrm{A}, \mathrm{B}, \mathrm{C}, \mathrm{D}$ and $j=\mathrm{E}, \mathrm{F}, \mathrm{G}, \mathrm{H}$ for a total of 80 fitting parameters. Since SRM 1967a will be certified as a sampled distribution, only average characteristics are of interest.

The data analysis included both sets of data taken in the $\mathrm{SiC}$ furnace as well as the data taken in the three-zone furnace. The $\mathrm{SiC}$ furnace runs used the thermoelement Pt67-7 (' $Z$ ') as the reference while the thermoelement Pt67-8 ('A') was used for the three-zone furnace data. The sources of the single-pair emf data are summarized in Table 1 showing which thermoelements were measured in each of the two furnaces and in which run. For the five Pt67 cuts and four Pt67a cuts, there are twenty possible unique pair combinations which may be formed as thermocouples. As shown in Table 1, only eight of those combinations were directly measured in the experimental runs. However, by making simple subtractions of the Pt67a-Pt67 pair data in combination with other Pt67 pair data, all twenty possible combinations may be calculated. The basis for calculating these combinations is shown in Table 2. 
Table 2. The source of all twenty possible Pt67a vs. Pt67 pair combinations as derived from the three experimental furnace runs. The individual letter designations are those defined in Table 1. The thermocouple 'Pair' designations are those formed by combining one letter from a Pt67a thermoelement with another letter from a Pt67 thermoelement. Those pair combinations that were measured directly are designated by 'Direct'. All other combinations are calculated as a difference between two separate Direct measurements, one Pt67a vs. Pt67 pair and one Pt67 vs. Pt67 pair.(e.g. EB=EA-BA, etc.).

\begin{tabular}{ccccc} 
Index & Pair & 3-Zone & SiC-1 & SiC-2 \\
\hline 1 & EA & Direct & EZ-AZ & \\
2 & EB & EA-BA & & \\
3 & EC & EA-CA & & \\
4 & ED & EA-DA & EZ-DZ & \\
5 & EZ & & Direct & \\
6 & FA & Direct & & FZ-AZ \\
7 & FB & FA-BA & & FZ-BZ \\
8 & FC & FA-CA & & FZ-CZ \\
9 & FD & FA-DA & & FZ-DZ \\
10 & FZ & & & Direct \\
11 & GA & Direct & & GZ-AZ \\
12 & GB & GA-BA & & GZ-BZ \\
13 & GC & GA-CA & & GZ-CZ \\
14 & GD & GA-DA & & GZ-DZ \\
15 & GZ & & & Direct \\
16 & HA & Direct & HZ-AZ & \\
17 & HB & HA-BA & & \\
18 & HC & HA-CA & & \\
19 & HD & HA-DA & HZ-DZ & \\
20 & HZ & & Direct & \\
\hline
\end{tabular}

There were a total of 166 Pt67a vs. Pt67 thermoelement pairs measured from the three experimental furnace runs at temperatures from $0{ }^{\circ} \mathrm{C}$ to $1070{ }^{\circ} \mathrm{C}$. The distributions of these data for $\Delta E_{i j}(t)$ are shown in Figure 3. The upper and lower limits of $\pm\left[0.2 \mu \mathrm{V}+\left(0.75 \mathrm{nV} /{ }^{\circ} \mathrm{C}\right) \times t\right]$ shown on the figure exclude about 8 pairs or approximately $5 \%$ of the data. The distribution is skewed slightly positive since all measurement pairs outside of the $95 \%$ symmetric bounds are positive. However, taken as a whole over all temperatures, there are slightly more negative values than positive, 89 and 77 respectively. The aggregated distribution is skewed such that the overall mean is $-0.02 \mu \mathrm{V}$ and a median is $-0.19 \mu \mathrm{V}$. The origin of the skew appears to be related to an obvious bifurcation between the three-zone furnace data and the $\mathrm{SiC}$ furnace data, with the former being predominately negative. 


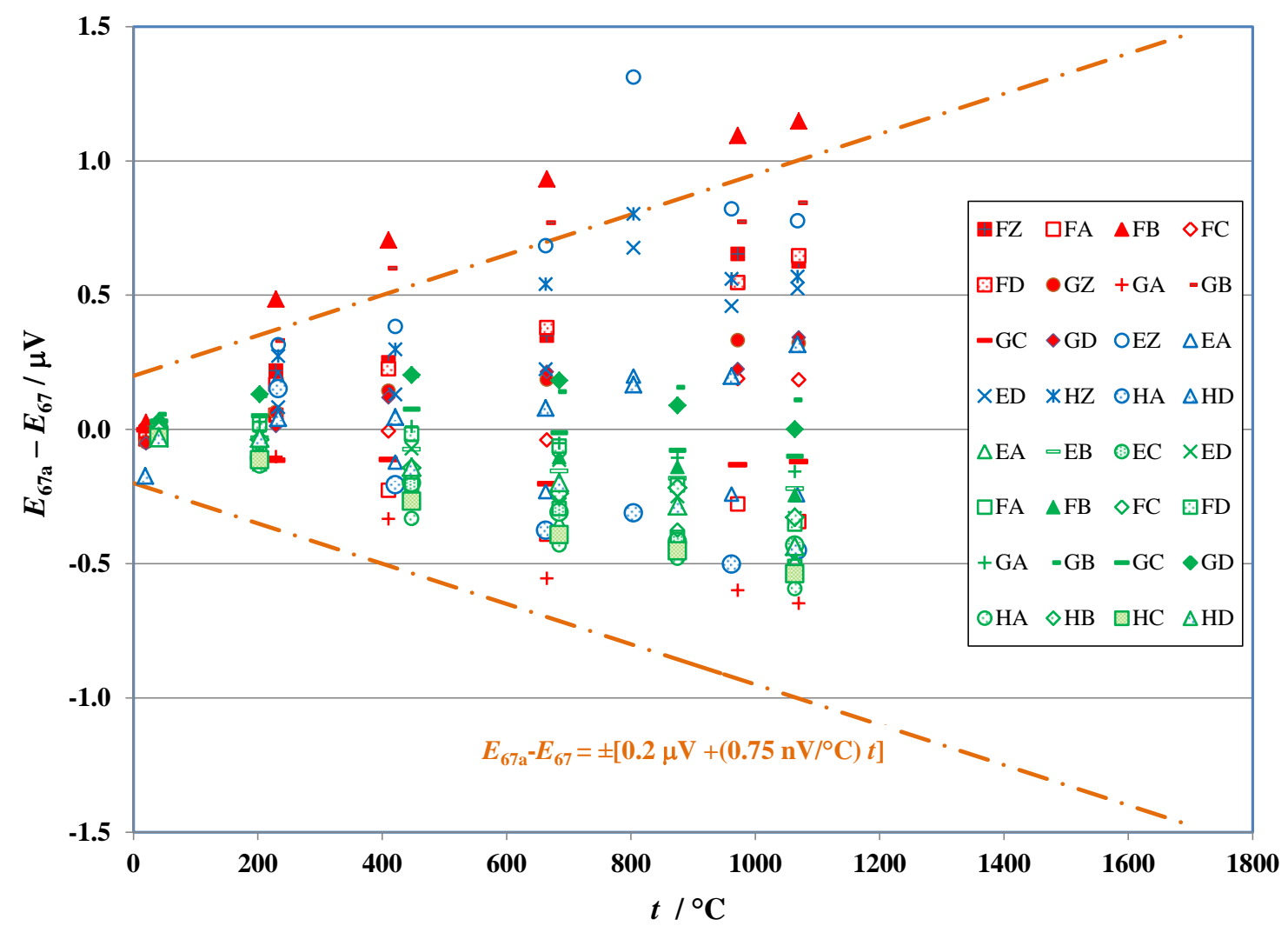

Figure 3. Compilation of thermoelectric voltages for all possible Pt67a vs. Pt67 thermoelement combinations from all three experimental furnace runs. There are 20 unique thermoelement combinations (see Table 2) distributed as 32 occurrences over the three furnaces runs: Green three-zone; Blue SiC-1; Red SiC-2. The upper and lower bounds given by the dashed-dotted lines include approximately $95 \%$ of the 166 total measurements over all temperatures.

The distribution for the low temperature data is shown in Figure 4. All of the data falls well within the stated uncertainties. 


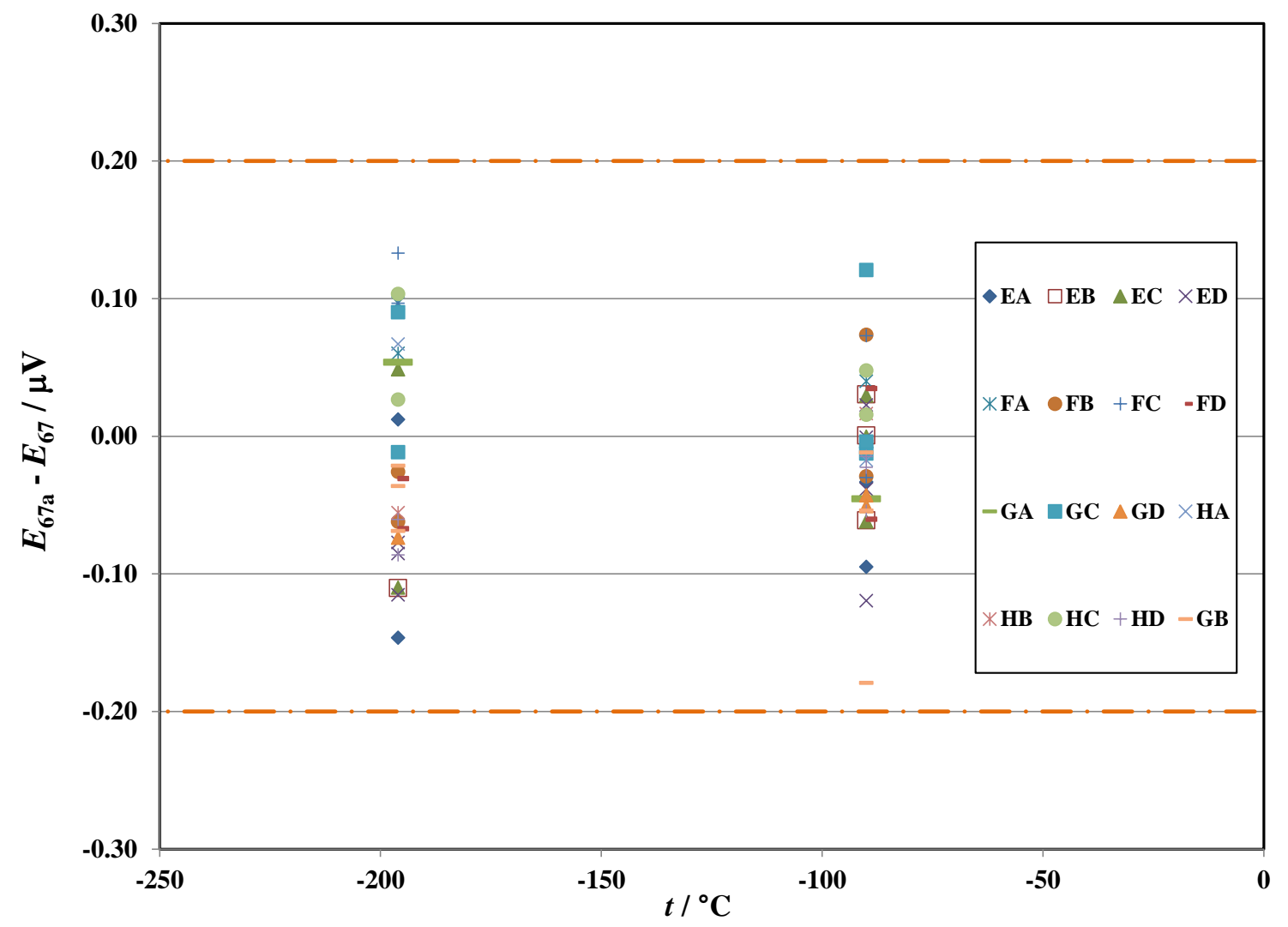

Figure 4. Compilation of thermoelectric voltages for all possible Pt67a vs. Pt67 thermoelement combinations from all three experimental low temperature runs. The upper and lower bounds given by the dashed-dotted lines include all of the 63 total combinations over both temperatures.

The data can be reduced by calculating averages of the differences for Pt67a thermoelements and Pt67 thermoelements from the reference wire, 'A' for the three-zone furnace data and ' $\mathrm{Z}$ ' for the $\mathrm{SiC}$ furnace data. These two averages are then subtracted from each other for each furnace set to derive the difference between Pt67a and Pt67 group averages which are independent of the choice in reference wire. The resulting statistics are shown in Figure 5 for the three furnace runs shown as three distributions. The negative values for the three-zone furnace data are again in contrast to the $\mathrm{SiC}$ furnace data. The emf differences are extrapolated to $1700{ }^{\circ} \mathrm{C}$ by fitting the data to quadratic functions of the form given by Eqn. 2. 


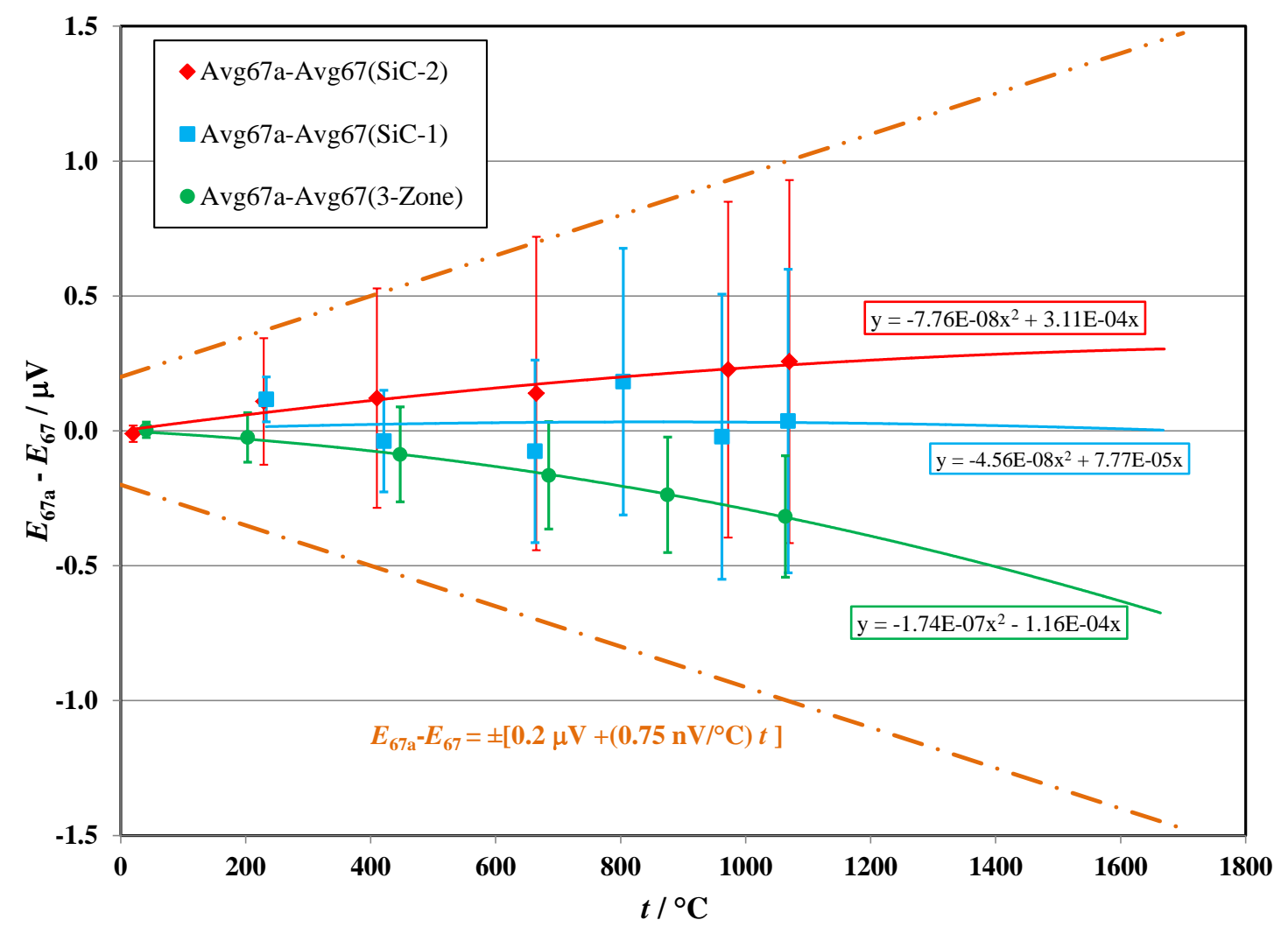

Figure 5. The differences in the mean values for Pt67a and Pt67 thermoelements as distributions in each of the three main furnace comparisons, three-zone (Green), SiC-1(Blue) and SiC-2 (Red).

In order to evaluate a possible furnace-dependent effect, we cull the pair data from Figure 3 to eliminate all ambiguity in the choice of the Pt67 reference cut, leaving only cut \#8, or wire 'A', which was present in all three furnace runs. The results of that culling are shown in Figure 6. When viewed with respect to this particular Pt67 reference wire, there are no clear systematic differences between the $\mathrm{SiC}$ and three-zone furnace data. Simple quadratic fits are again used to extrapolate up to $1700{ }^{\circ} \mathrm{C}$ with no strongly divergent trends. It is also evident that for the most part the Pt67a thermoelements are negative with respect to wire A, (Pt67 cut \#8). 


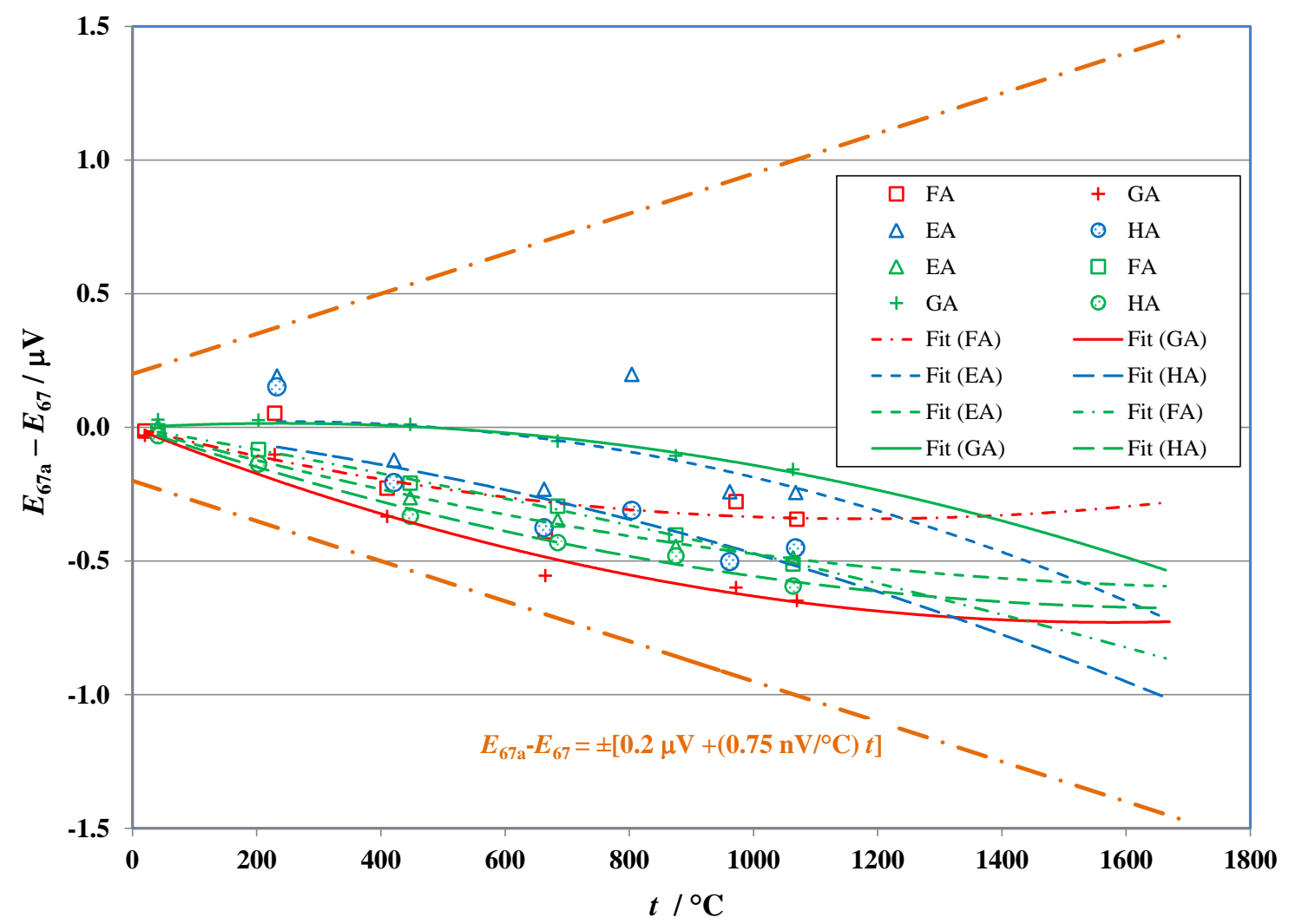

Figure 6. Pt67a thermoelement combinations with Pt67 cut \# 8, wire 'A'.

It is also useful to evaluate the self-consistency of the Pt67 thermoelement data by itself, independent of Pt67a. This is again done with respect to the common reference wire, cut $\# 8$ or ' $A$ ', as it is used in all the furnace runs. The results of these thermoelement pair combinations are shown in Figure 7. In this case a marked difference is evident between the three-zone furnace data and the $\mathrm{SiC}$ furnace data. The observed emf values are considerably negative when measured in the $\mathrm{SiC}$ furnace, while the same combinations are only slightly negative when measured in the three-zone furnace. Furthermore, the dispersion of the $\mathrm{SiC}$ data is 4 to 5 times greater than what we observed in the three-zone furnace data. Based on the Pt67a data in Figure 6, any instability of the reference wire A from run to run is $<0.25 \mu \mathrm{V} \pm 0.25 \mu \mathrm{V}$. The simplest explanation for the differences observed in the Pt67 distributions from the two furnaces is therefore thermoelectric changes in the Pt67 thermoelements B, C, and D between the time of the three-zone measurements and the later $\mathrm{SiC}$ measurements. However, since the $\mathrm{SiC}$ data are all negative with respect to the three-zone data, the physical origin of these changes must be associated with some lower relative degree of physical strain and or additional oxidation of certain impurities in these thermoelements. 


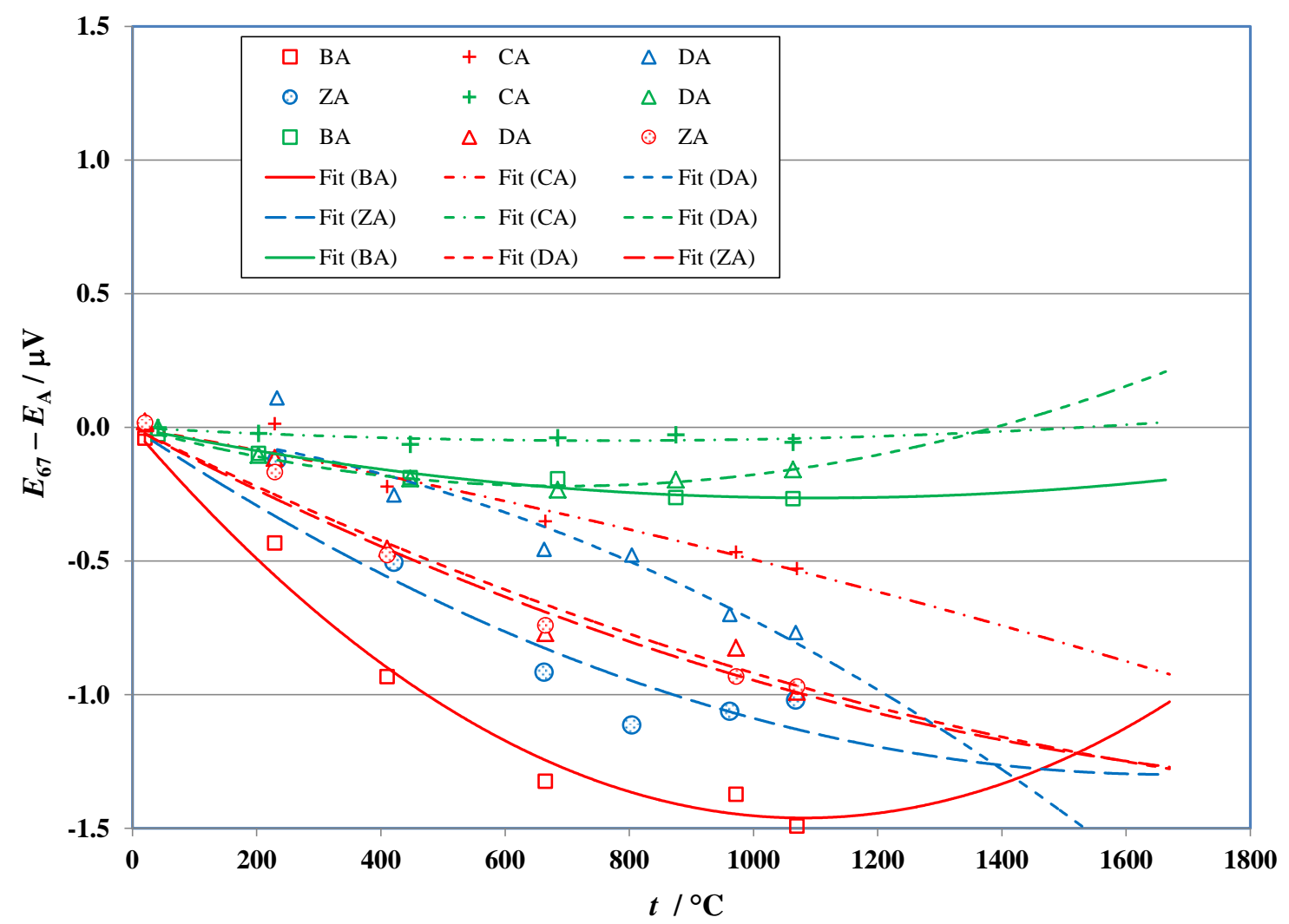

Figure 7. Pt67 thermoelement combinations with reference wire Pt67-8 ('A').

Given the limited amount of thermoelectric comparison data available for this certification, there are practical limits to the degree of equivalence that may be established. There are, however, several general features to the data that we observe:

- The reference wire Pt67-8 ('A') is the most thermoelectrically positive of all wire samples tested.

- Establishing the degree of thermoelectric equivalence between the two lots of wire is limited by the variability that we observe in our 5 samples of the original Pt67.

- The observed variability in the samples of Pt67a, in contrast, is within reasonable limits of $\pm 0.25 \mu \mathrm{V}$.

- Differences between the three-zone furnace measurements and SiC furnace measurements are likely due to changes that occurred in several of the Pt67 test thermoelements during and or in-between the times which these tests occurred.

For a reference junction at $0{ }^{\circ} \mathrm{C}$, the NIST certified equivalence between the thermoelectric voltages of Pt67a and Pt67 is stated as follows:

$$
E_{67 a}(t)-E_{67}(t)=0 \mu \mathrm{V}, \text { and } U_{95}(t)=\left\{\begin{array}{c}
0.2 \mu \mathrm{V} \text { for }-196{ }^{\circ} \mathrm{C}<t<0{ }^{\circ} \mathrm{C}, \\
0.2 \mu \mathrm{V}+0.75 \mathrm{nV}\left(t /{ }^{\circ} \mathrm{C}\right) \text { for } 0{ }^{\circ} \mathrm{C} \leq t \leq 1700{ }^{\circ} \mathrm{C},
\end{array}\right.
$$


where $t$ is the temperature on the International Temperature Scale of 1990.

\section{Uncertainties}

Because we measure only the difference in emf, many of the uncertainties typical for a comparison calibration of thermocouples are negligible. In particular, the uncertainty of the reference thermometer and the gain of the DMM may be neglected. Significant measurement errors may be caused by:

- $\quad$ stray thermal emf, due to inadequate correction of thermal emf offsets;

- fluctuations in the DMM zero reading; and

- changes in emf due to a combination of temperature gradients near the measuring junction, coupled with changes in Seebeck coefficient caused by the welding process.

However, all of these effects are equally likely to affect either the SRM 1967 cuts or the SRM 1967a cuts. On average, there will be no net effect on the inferred emf difference between SRM 1967 and 1967a. There will be a possible increase in the variability from cut to cut, with a resulting increase in uncertainty.

The uncertainty statement provided accounts for:

- the variability of the SRM 1967a lot from its average value, and

- the variability of the SRM 1967 from its average value, and

- the reproducibility of the difference between the emf of SRM 1967a and SRM 1967.

For temperatures above $0{ }^{\circ} \mathrm{C}$ the spread of observed differences in emf between the two lots of material increases, roughly in proportion to the temperature expressed in ${ }^{\circ} \mathrm{C}$. For the purposes of this discussion, we base all calculations on the observed deviations at or near $1060{ }^{\circ} \mathrm{C}$. For any given temperature, the standard uncertainty for the lot variability of SRM 1967a, $u_{\mathrm{L}}$, is assumed to be the standard deviation of the emf values for the four cuts of SRM 1967a. This statistic was reasonably consistent between the three main furnace runs, $0.19 \mu \mathrm{V}$ for the three-zone, $0.15 \mu \mathrm{V}$ for the SiC- 1 and $0.22 \mu \mathrm{V}$ for the SiC2 runs. The effective degrees of freedom for these three Pt67a data sets were 3, 1, and 1 , respectively. Using these degrees of freedom as weights, we combine the three runs to yield an estimated Pt67a lot variability uncertainty of $0.16 \mu \mathrm{V}$.

The standard uncertainty for the variability of the SRM 1967 from its average value is also assumed to be the standard deviation of the emf values for the four cuts of SRM 1967 (those other than cut 7 or ' $Z$ ') with cut $Z$ taken as a reference. In contrast to the observed distributions for Pt67a, this statistic for the Pt67 cuts was inconsistent between the three main furnace runs, $0.12 \mu \mathrm{V}$ for the three-zone, $0.54 \mu \mathrm{V}$ for the SiC-1 and $0.64 \mu \mathrm{V}$ for the SiC-2 runs, again using values from $1060{ }^{\circ} \mathrm{C}$. The effective degrees of freedom for these three Pt67 data sets were 3, 1, and 3, respectively. Again using these degrees of freedom as weights, we combine the three runs to yield an estimated lot variability uncertainty for our samples of Pt67 of $0.47 \mu \mathrm{V}$.

Additionally, a value of $40 \mathrm{nV}$ is included to account for random and quasi-random measurement errors from noise and stray emfs in the measuring system. An estimate may then be calculated for the combined standard uncertainty in the measured difference 
between the samples of the two lots from the above calculated uncertainty components of $0.16 \mu \mathrm{V}, 0.47 \mu \mathrm{V}$ and $0.04 \mu \mathrm{V}$, yielding $0.50 \mu \mathrm{V}$ estimated standard uncertainty and $U_{95}\left(1060{ }^{\circ} \mathrm{C}\right)=1.0 \mu \mathrm{V}(k=2)$ expanded combined uncertainty at $1060{ }^{\circ} \mathrm{C}$.

The $U_{95}(t)$ expanded combined uncertainties represent a confidence interval of approximately $95 \%$, or a coverage factor of $k=2$ [13]. The uncertainty bounds $\pm U_{95}(t)$ have values of approximately $\pm 1.48 \mu \mathrm{V}$ at $1700{ }^{\circ} \mathrm{C}$ when assumed to increase linearly with the temperature $t$. Virtually all thermocouple alloys have an intrinsic inhomogeneity greater than these values, so the SRM 1967a lot is highly suitable as a reliable thermoelectric reference.

\section{Use of SRM 1967a}

As discussed in the Introduction, SRM 1967a provides a reliable thermoelectric reference from $-223{ }^{\circ} \mathrm{C}(50 \mathrm{~K})$ up to approximately $1700{ }^{\circ} \mathrm{C}$.

The material should be electrically annealed, as described in section 2 . The wire must be protected from chemical contamination and mechanical strain. At temperatures above approximately $300{ }^{\circ} \mathrm{C}$, contamination may occur via vapor-phase transport of volatile oxides, metals, or other compounds. Sheathing the wire in high-purity alumina, avoiding exposure to metals, and operating in a non-reducing gas environment offers the best protection to the wire. Users are cautioned that at temperatures above $1300{ }^{\circ} \mathrm{C}$, impurities may diffuse over time into the platinum from even the best alumina [14],[1]. Once the wire has been contaminated, there is rarely any mechanism to remove the contamination.

References [15] and [16] provide guides to good thermocouple practice. The introductory sections on each thermocouple type in NIST Monograph 175 [3] provide additional information.

Typically, samples are tested with SRM 1967a as the negative leg of a thermocouple and the test sample as the positive leg. To correct the measured emf to the emf that would have been measured against the original SRM 1967 (Pt67), a correction would be applied as follows:

$$
E(\text { Test vs. Pt67 })=E(\text { Test vs. Pt67a })+E_{67 a-67} .
$$

The NIST SRM 1967 a certification for the value of $E_{67 a-67}$ is 0 to within the stated uncertainties for the Pt67a lot of reference wire, as stated in Eqn. 3, so no explicit correction is necessary. Some customers may still wish to establish a more specific correction based on specific wire to wire comparisons that they establish based on their own measurements. In such cases the correction would be stated according to the convention shown in Eqn. 4. 


\section{Resistance Ratio Measurements}

The resistance ratio measurements described here are given for supplemental information purposes only and are not part of the certified results reported above. These results are provided for only one sample cut from the Pt67a spool, and are hence of no significance from the statistical sampling standpoint.

The trailing-end cut of the SRM 1967a spool was used for supplemental measurements of the resistance ratio. This sample, Cut \#33 or 'Pt67a-33', was approximately $22.5 \mathrm{~cm}$ in length. The sample was electrically annealed using the same procedure (see section 2) as used for the $1 \mathrm{~m}$ thermoelectric test samples.

A four-bore alumina insulator was prepared for use with the sample. The insulator was cut to $5 \mathrm{~cm}$ in length, cleaned, dried, and baked at $900{ }^{\circ} \mathrm{C}$ before use. The wire was cut in half and each half re-formed into a single-bend parallel loop to fit the alumina insulator. The two halves were then threaded into the insulator and re-welded together at one end forming a complete four-loop parallel circuit conductor. At each of the two free ends, two additional small lengths of $0.25 \mathrm{~mm}$ diameter Pt wire were welded to serve as leads for the four-wire measurement. The completed resistor assembly is shown in Figure 5.

The resistor assembly was placed in a quartz protection tube and repeatedly re-annealed in air using a single-zone furnace. The annealing time and temperature schedule was variable, as shown in Table 3. In addition to the Pt67a-33 sample, two other resistor assemblies were fabricated in the same manner using two adjacent cuts (Cuts \#12 and \#13) from the original SRM 1967 spool. We identify these samples as 'Pt67-12' and 'Pt67-13' and the furnace annealing schedule used for these samples is also shown in Table 3. All three resistor assemblies exhibited stable resistances of $R(273.16 \mathrm{~K}) \cong 0.1 \Omega$.

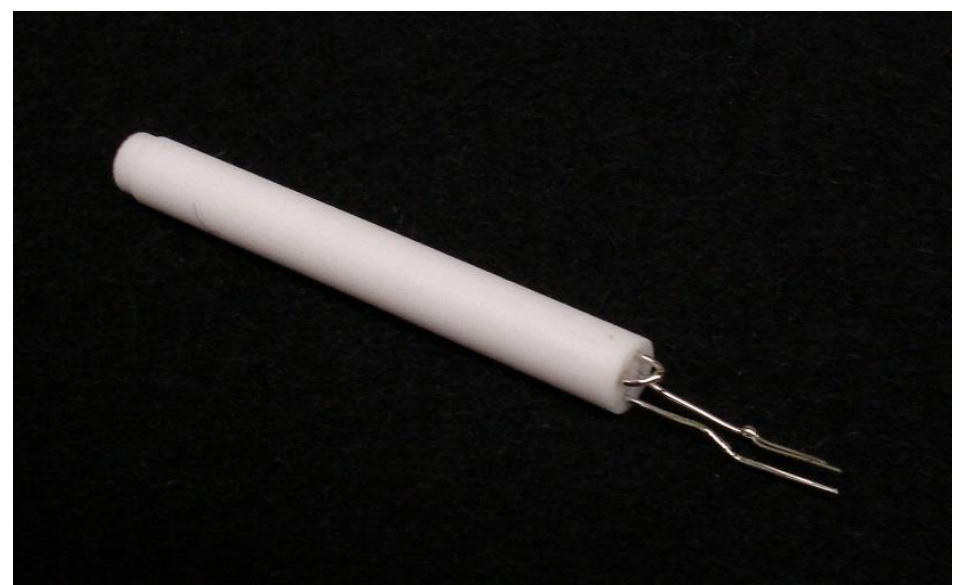

Figure 5. A completed resistor assembly from a $22 \mathrm{~cm}$ length of wire and a four-bore alumina insulator.

Two separate series of resistance ratio measurements were performed on each of the three Pt samples. The first was a ratio of the resistance at the water triple point (WTP), $T=273.16 \mathrm{~K}$, to the resistance at the normal boiling point of liquid helium $\left({ }^{4} \mathrm{He} \mathrm{NBP}\right)$, $T \cong 4.22 \mathrm{~K}$ or 


$$
X_{\mathrm{RR}}=\frac{R\left({ }^{4} \mathrm{He} \mathrm{NBP}\right)}{R(\mathrm{WTP})} .
$$

This is usually referred to as the 'residual resistance ratio' [17] in the literature; however, for the high purity samples considered here, the resistance $R(4.22 \mathrm{~K})$ is actually $\approx 8 \%$ to $10 \%$ larger than the true residual resistance $R(0 \mathrm{~K})$. We use $X_{\mathrm{RR}}$ as defined in Eqn. 6 in order to be consistent with other values reported in the literature. We neglect the $\approx 40 \times 10^{-6}$ difference between our WTP normalization and the more common ice-point normalization.

The second resistance ratio was derived from the gallium melting point (GaMP), $T_{90}=302.9146 \mathrm{~K}$, and the WTP. This is an ITS-90 defining fixed point, but NIST Ga cells are actually constructed as triple points, so a $2 \mathrm{mK}$ correction is applied [18]. The standard notation for this resistance ratio is given by

$$
W(\mathrm{GaMP}) \equiv \frac{R(\mathrm{GaMP})}{R(\mathrm{WTP})} .
$$

The ITS-90 reference function for Standard Platinum Resistance Thermometers (SPRTs) defines the reference value $W_{\mathrm{r}}(\mathrm{GaMP}) \equiv 1.11813889$.

For the $X_{\mathrm{RR}}$ measurements, each resistor assembly was mounted in an aluminum heat sink at the bottom inside of a $12.7 \mathrm{~mm}$ sealed borosilicate glass tube. The glass tube was used for immersion within both the WTP cell and a liquid helium dewar allowing the samples to remain mechanically unperturbed during the cycling between temperatures. Prior to use in liquid helium, the tube was evacuated and flushed with helium gas to $\approx 101 \mathrm{kPa}$ pressure. The internal pressure at $4.2 \mathrm{~K}$ was $\approx 1 \mathrm{kPa}$, which allowed a sufficient heat exchange to reduce self heating to negligible levels.

Measurements of $W(\mathrm{GaMP})$ were accomplished using $7.5 \mathrm{~mm}$ diameter borosilicate adapter tubes similar to those used at NIST for SRM 1750 SPRTs [19]. Corrections were applied for the observed self-heating, the static pressure head of the Ga cell and the difference between triple point and melting point temperatures.

The resistance measurements were performed using an $\mathrm{AC}$ resistance bridge operating at $30 \mathrm{~Hz}$ and $90 \mathrm{~Hz}$ using a $1 \Omega$ reference resistor. Excitation currents were $20 \mathrm{~mA}$ and 28.3 $\mathrm{mA}$ at $273.16 \mathrm{~K}, 14.14 \mathrm{~mA}$ and $20 \mathrm{~mA}$ at the $302.91 \mathrm{~K}$, and $50 \mathrm{~mA}$ and $70.7 \mathrm{~mA}$ at 4.2 $\mathrm{K}$. A DC resistance measurement was also performed at $4.2 \mathrm{~K}$ in order to verify the quadratic nature of the observed frequency dependence. The observed resistances at $30 \mathrm{~Hz}$ were corrected by $\approx 0.2 \%$ to $0.3 \%$ to be consistent with DC resistance values. The relative standard uncertainty for $X_{\mathrm{RR}}$ measurements is estimated at $0.1 \%$. The relative standard uncertainty in the $W(\mathrm{GaMP})$ measurements was $1.4 \times 10^{-6}$ which was limited by statistical uncertainties resulting from random bridge noise and a relatively low signal level. 
The results of the ratio measurements are summarized in Table 3 . The first furnace anneal of Pt67a-33 was at $700{ }^{\circ} \mathrm{C}$ for $1.25 \mathrm{~h}$, followed by two subsequent anneals with a measurement of $X_{\mathrm{RR}}$ following each annealing treatment as shown. The one GaMP ratio measurement followed the final furnace anneal at $800{ }^{\circ} \mathrm{C}$. The low values observed for Pt67a-33 relative to those of the Pt67 samples is consistent with the higher impurity concentrations present in the SRM 1967a wire lot. Attempts to perform additional annealing on Pt67a-33 for extended time periods of time (e.g. $\gtrsim 24 \mathrm{~h}$ ) at temperatures under $500{ }^{\circ} \mathrm{C}$ had no effect on the subsequently measured value for $X_{\mathrm{RR}}$.

Table 3. Summary of contemporary results for resistance ratio measurements of two samples from Pt67 and one from Pt67a together with historical values for Pt67.

\begin{tabular}{lcccccc}
\hline Sample ID & $\boldsymbol{T}_{\text {anneal }} /{ }^{\circ} \mathbf{C}$ & $\boldsymbol{t}_{\text {anneal }} /$ hrs. & $\boldsymbol{X}_{\mathbf{R R}}$ & $\boldsymbol{W}(\mathbf{G a M P})$ & $\left.\boldsymbol{W ( 1 0 0}{ }^{\circ} \mathbf{C}\right)$ & Reference \\
\hline \hline Pt67 & 600 & 1.0 & 3500 & & 1.39269 & {$[5]$} \\
Pt67-12 & 700 & 0.5 & 3489 & 1.11814116 & 1.392780 & This Work \\
Pt67-13 & 700 & 1.25 & 4300 & 1.11815352 & 1.392821 & This Work \\
Pt67a-33 & 700 & 1.25 & 2257 & & & This Work \\
Pt67a-33 & 700 & 1.2 & 2614 & & & This Work \\
Pt67a-33 & 800 & 1.0 & 2755 & 1.11813557 & 1.392762 & This Work \\
\hline
\end{tabular}

${ }^{\dagger}$ Average values of 5 samples taken from the original SRM wire lot, from Powell, et. al. [5].

The contemporary measurements of $X_{\mathrm{RR}}$ for the two Pt67 samples are consistent with the archival values from Powell, et. al. [6], allowing for the differences in the annealing temperatures. Assuming the Pt67 samples used by Powell, et. al. in 1973 and those used in this work were chemically equivalent, the data in comparison suggest that annealing at $700{ }^{\circ} \mathrm{C}$ for 30 minutes yields a physical state for the wire roughly equivalent to that produced by annealing at $600{ }^{\circ} \mathrm{C}$ for $60 \mathrm{~min}$. If it is also assumed that the adjacent cuts, Pt67-12 and -13 were equivalent, longer annealing times continue to increase the observed $X_{\mathrm{RR}}$ values above the range observed by Powell, et. al. In contrast, the much lower $X_{\mathrm{RR}}$ values observed for Pt67a-33 after extensive annealing treatments are probably due to the influence of the relatively high iron impurity concentration (i.e. $1.6 \mu \mathrm{g} / \mathrm{g}$ ) in the Pt67a wire lot. The continued incremental improvement in the residual resistance with annealing suggests that some oxidation of the iron was taking place, in effect taking those impurities out of the Pt solid solution.

The $W(\mathrm{GaMP})$ measurements were similar to what would be expected for these samples given the experience of Powell et. al. as expressed in their value for $W\left(100{ }^{\circ} \mathrm{C}\right)$. The sample Pt67a-33 was slightly below the value defined for the ITS-90, while samples Pt67-12 and -13 were substantially above the ITS-90 reference value. It is also as expected that the $X_{\mathrm{RR}}$ values correlate with the $W(\mathrm{GaMP})$ values given that the sample-tosample variations in both ratios are governed by the impurity concentrations [20]. 


\section{Acknowledgements}

The authors wish to acknowledge the assistance of Mr. Ellery Murdock during the preparation of the samples for the residual resistance measurements. We also thank Ms. Michal Chojnacky for performing the $W(\mathrm{GaMP})$ measurements on these samples. Chris Meyer provided helpful comments on the manuscript. We gratefully acknowledge Mr. George Burns for his suggestions and assistance in performing portions of this work. 


\section{References}

[1] ASTM Manual on the Use of Thermocouples in Temperature Measurement, ASTM MNL-12, 4th Ed., ASTM, West Conshohocken, PA (1993) 290 p.

[2] Preston-Thomas, H., The International Temperature Scale of 1990 (ITS-90), Metrologia 27, 3-10 (1990); Erratum, ibid., 107.

[3] Burns, G. W., Scroger, M. G., Strouse, G. F., Croarkin, M. C., and Guthrie, W. F., Temperature-Electromotive Force Reference Functions and Tables for the LetterDesignated Thermocouple Types Based on the ITS-90, Nat. Inst. Stand. Techn. Monograph 175 (1993).

[4] Wichers, E. The History of Pt 27, in Temperature: Its Measurement and Control in Science and Industry; Vol. 3; Herzfeld, C. M.., ed.; New York: Reinhold Publishing Corp. (1962) Part 1, pp. 259-262.

[5] Anon., New platinum standards, Natl. Bur. Stand. (U.S.) Tech. News Bull. 52, 62 (1968).

[6] Powell, R. L., Sparks, L. L., and Hust, J. G. Standard reference materials: standard thermocouple material, Pt-67: SRM-1967. Natl. Bur. Stand. (U.S.) Spec. Publ. 260-56 (1978).

[7] Rhys, D. W., and Taimsalu, P., Effect of alloying additions on the thermoelectric properties of platinum, Engelhard Tech. Bull. 10, 41-47 (1969).

[8] Cochrane, J., Relationship of chemical composition to the electrical properties of platinum, Engelhard Tech. Bull. 11, 58-71 (1969). Also in: Temperature: Its Measurement and Control in Science and Industry; Vol. 4; Plumb, H. H., ed.; Pittsburgh: Instrument Society of America (1972), pp. 1619-1632.

[9] Aliotta, J., Effects of impurities on the thermoelectric properties of platinum, Inst. and Control Systems, 106-107 (March 1972).

[10]Sigmund-Cohn Corp., Mount Vernon, N.Y., Bar \#240461, purchased August 2006.

[11]Ripple, D. C. and Burns, G. W., Standard Reference Material 1749: Au/Pt Thermocouple Thermometer, Natl. Inst. Stand. Technol. Spec. Publ. 260-134 (2002).

[12] Burns, G. W. and Scroger, The Calibration of Thermocouples and Thermocouple Materials, NIST Special Publication 250-35, National Institute of Standards and Technology, Gaithersburg, MD, (April 1989). pp. 44 \& 72.

[13] Guide to the Expression of Uncertainty in Measurement, Intern. Org. for Standardization (ISO), Switzerland (1993), p. 59.

[14] Walker, B. E., Ewing, C. T., and Miller, R. R., Thermoelectric instability of some noble metal thermocouples at high temperatures, Rev. Sci. Instrum. 33, 10291040 (1962). 
[15] Bentley, R. E., Changes in Seebeck coefficient of Pt and Pt $10 \% \mathrm{Rh}$ after use to $1700{ }^{\circ} \mathrm{C}$ in high-purity polycrystalline alumina, Int. J. Thermophysics 6, 83-99 (1985).

[16] Handbook of Temperature Measurement Vol. 3: The Theory and Practice of Thermoelectric Thermometry, R. E. Bentley, ed., Springer (1998), 245 p.

[17] Ekin, J. W., Experimental Techniques for Low Temperature Physics, Section 6.3.4, Oxford University Press, Oxford UK (2006) 673 pp.

[18] Strouse, G. F., Standard Reference Material 1751: Gallium Melting-Point Standard, NIST Special Publication 260-157, US Gov. Printing Office (2004) $20 \mathrm{pp}$.

[19] Tew, W. L., and Strouse, G. F., SRM 1750: Standard Platinum Resistance Thermometers, 13.8033 K to 429.7485 K, NIST Spec. Publ. 260-139, 37 pp. (2001).

[20] Tew, W. L., Murdoch, W. E., Chojnacky, M. J. and Ripple, D. C., The Residual Resistance Ratio of High-Purity Platinum, Proceedings of the National Conference of Standards Laboratories International, Aug 22-25, 2011, Washington, DC, to be published (2011). 
Appendix I. Sample Certificate 


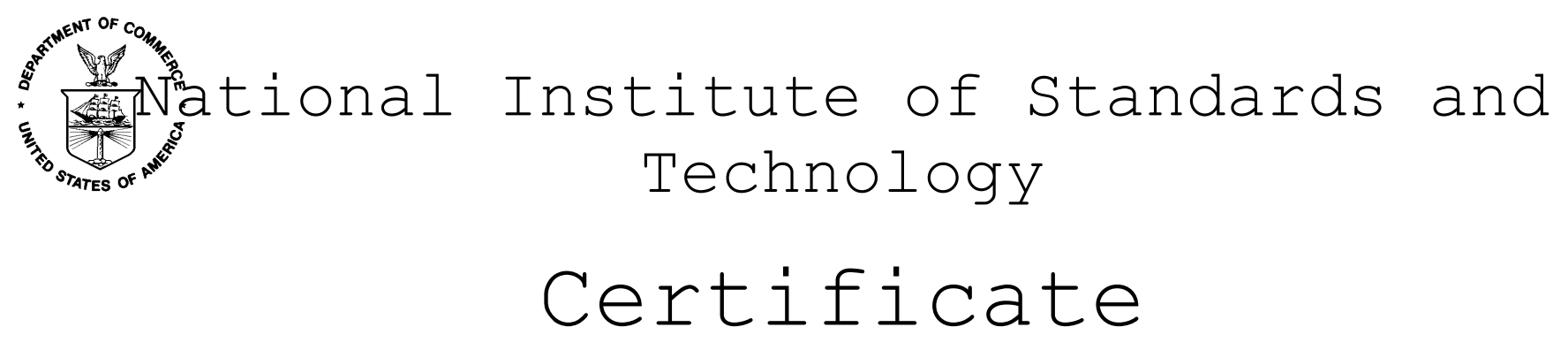

\title{
Standard Reference Material ${ }^{\circledR}$ 1967a
}

\author{
High-Purity Platinum Thermoelement
}

This Standard Reference Material (SRM) is a high-purity (approximately $99.999 \%$ mass fraction) platinum wire, $0.51 \mathrm{~mm}$ in diameter and $1 \mathrm{~m}$ long, suitable for use as a standard reference thermoelement for calibrations of base and noble metal thermocouple materials in the temperature range $-196{ }^{\circ} \mathrm{C}$ to approximately $1700{ }^{\circ} \mathrm{C}$. NIST Monograph 175 [2] gives standardized thermoelectric voltage versus temperature relations for thermocouples, based on the International Temperature Scale of 1990 (ITS-90) [1]. SRM 1967a replaces the former thermoelectric standard SRM 1967. Historically, SRM 1967 has been commonly designated Pt-67; similarly; SRM 1967a may be referred to as Pt-67a.

Certified Electromotive Force Relation: The certified electromotive force (emf) values obtained for SRM 1967a are stated relative to the average thermoelectric response of the former SRM 1967. For a reference junction at $0{ }^{\circ} \mathrm{C}$, the certified difference between the emfs of SRM 1967, $E_{67}$, and SRM 1967a, $E_{67 a}$, and its expanded uncertainties are given as:

$$
E_{67 a}(t)-E_{67}(t)=0 \mu \mathrm{V}, \text { and } U_{95}(t)=\left\{\begin{array}{c}
0.2 \mu \mathrm{V} \text { for }-196{ }^{\circ} \mathrm{C}<t<0{ }^{\circ} \mathrm{C}, \\
0.2 \mu \mathrm{V}+0.75 \mathrm{nV}\left(t /{ }^{\circ} \mathrm{C}\right) \text { for } 0{ }^{\circ} \mathrm{C} \leq t \leq 1700{ }^{\circ} \mathrm{C}
\end{array}\right.
$$

where $t$ is the temperature on the International Temperature Scale of 1990. The certified equivalence is for the emf produced by the samples of SRM 1967a relative to that of SRM 1967 and is uncertain within the bounds of the expanded uncertainty, $\pm U_{95}(t)$. The uncertainties account for: the variability of the SRM 1967a batch from its average value; the variability of the SRM 1967 batch from its average value; and the reproducibility of the difference between the emfs of SRM 1967 and SRM 1967a [3,4]. The $U_{95}(t)$ expanded uncertainties represent a confidence interval of approximately $95 \%$, or a coverage factor of 2 . The uncertainty bounds $\pm U_{95}(t)$ have values of approximately $\pm 1.48 \mu \mathrm{V}$ at $1700^{\circ} \mathrm{C}$. The measurands are the electromotive force relation values for the platinum wire. The values are metrologically traceable to the SI unit for voltage.

Expiration of Certification: The certification of SRM 1967a is valid indefinitely, within the measurement uncertainties specified, provided the SRM is handled and stored in accordance with the instructions given in this certificate (see "Instructions for Handling, Storage, and Use"). Accordingly, periodic recalibration or recertification of this SRM is not required. The certification is nullified if the SRM is damaged, contaminated, or otherwise modified.

The coordination of the technical measurements leading to the certification of this SRM was under the direction of K.M. Garrity and D.C. Ripple of the NIST Sensor Science Division.

Preparation of and analytical measurements on the SRM were performed by K.M. Garrity, D.C. Ripple, and W.L. Tew of the NIST Sensor Science Division.

Support aspects involved in the issuance of this SRM were coordinated through the NIST Measurement Services Division. 
Maintenance of SRM Certification: NIST will monitor this SRM over the period of its certification. If substantive technical changes occur that affect the certification before the expiration of this certificate, NIST will notify the purchaser. Registration (see attached sheet) will facilitate notification.

A NIST Special Publication describes the preparation, characterization, and use of SRM 1967a [3].

\section{WARNING TO USERS:}

Electrical annealing of the platinum wire requires application of lethal voltages to the wire. Appropriate safeguards should be in place to prevent contact of personnel with lethal voltages.

\section{INSTRUCTIONS FOR HANDLING, STORAGE, AND USE}

Handling: The SRM 1967a samples consist of high-purity platinum wire. The sample should be handled wearing powder-free gloves. Avoid chemical contamination and kinks in the wire.

Storage: SRM 1967a wires, as received, should be kept in the original box and bag, and stored at temperatures less than $30{ }^{\circ} \mathrm{C}$.

Use: Proper usage of this SRM requires careful annealing and handling. The recommended procedures are:

1. Clean with a wipe saturated with ethanol and air dry.

2. Suspend the wire in a clean, dust-free enclosure and connect to a current source.

3. Continuously increase the current until the wire is at a temperature of $1200{ }^{\circ} \mathrm{C}$, as measured by a ratio or disappearing-filament pyrometer with emissivity set to 0.3 (see "Warning" above).

4. Maintain this temperature for 10 minutes.

5. Slowly decrease the current until the wire appears red in color and only slightly incandescent.

6. Maintain this temperature for 60 minutes and then slowly cool to room temperature.

7. Care should be taken at all times to avoid unnecessary mechanical stresses of the wire.

8. High-purity (nominally $99.7 \%$ purity or higher) sintered alumina tubing is recommended for insulating and protecting the platinum wire during use at high temperatures. After assembling the wire in an insulating tube, re-anneal the assembly in a furnace for 60 minutes at $1100{ }^{\circ} \mathrm{C}$ followed by cooling to $450{ }^{\circ} \mathrm{C}$. The assembly should be maintained at $450^{\circ} \mathrm{C}$ for 12 hours or overnight and then cooled to room temperature.

Users are cautioned that at temperatures above $1300{ }^{\circ} \mathrm{C}$, impurities may diffuse over time into the platinum from even the best alumina. Once the wire has been contaminated at high temperature, there is rarely any mechanism to remove the contamination.

\section{PREPARATION AND ANALYSIS}

The wire used for SRM 1967a consisted of $32 \mathrm{~m}$ of $0.51 \mathrm{~mm}$ diameter platinum wire, obtained from a commercial vendor on a single spool. The SRM was prepared by cuts of the stock into $1 \mathrm{~m}$ lengths of wire. Each cut was packaged in a polyethylene bag. Four cuts of SRM 1967a, evenly spaced through the lot, were used as test samples. From a spool of the original stock for SRM 1967, four $1 \mathrm{~m}$ long cuts were used as reference samples. Each wire was electrically annealed by the procedure described in "Instructions for Handling, Storage, and Use".

Single-bore alumina insulators of nominal $99.7 \%$ purity (mass fraction) were used to hold and insulate the platinum wires. Lengths of copper wire, all from the same spool, were soldered on to form reference junctions. Finally, all eight of the test and reference samples were welded together with a hydrogen torch to form a common measuring junction.

The emf generated by various combinations of the eight platinum wires were measured at $-196{ }^{\circ} \mathrm{C},-90{ }^{\circ} \mathrm{C}$, ambient temperature, $200{ }^{\circ} \mathrm{C}, 450{ }^{\circ} \mathrm{C}, 700{ }^{\circ} \mathrm{C}, 900{ }^{\circ} \mathrm{C}$, and $1100{ }^{\circ} \mathrm{C}$. A total of $166 \mathrm{emf}$ comparison measurements were made over this range of temperature. Through statistical analysis of the data, we obtained measures of the thermoelectric homogeneity of the two lots of platinum wire and of the average emf of SRM 1967a relative to SRM 1967.

\section{HOMOGENEITY}

During the certification process, material homogeneity was assessed by statistical analysis of the thermoelectric comparison data. The stated uncertainties include components for the homogeneity of both SRM 1967 and 
SRM 1967a. Analysis and details are reported in ref. [3]. NIST performed thermoelectric homogeneity testing and measurements of thermoelectric voltage relative to SRM 1967 over the temperature range $-196{ }^{\circ} \mathrm{C}$ to $+1100{ }^{\circ} \mathrm{C}$.

\section{REFERENCES}

[1] Preston-Thomas, H.; The International Temperature Scale of 1990 (ITS-90); Metrologia, Vol. 27, pp. 3-10, (1990); see also Preston-Thomas, H.; The International Temperature Scale of 1990 (ITS-90); Metrologia, Vol. 27, p. 107, (1990).

[2] Burns, G.W.; Scroger, M.G.; Strouse, G.F.; Croarkin, M.C.; Guthrie, W.F.; Temperature-Electromotive Force Reference Functions and Tables for the Letter-Designated Thermocouple Types Based on the ITS-90, NIST Monograph 175 (1993).

[3] Garrity, K.M.; Ripple, D.C.; Tew, W.L.; SRM 1967a: High-Purity Platinum Thermoelement; NIST Special Publication 260-XXX (2013).

[4] JCGM 100:2008; Evaluation of Measurement Data - Guide to the Expression of Uncertainty in Measurement (ISO GUM 1995 with Minor Corrections); Joint Committee for Guides in Metrology (JCGM) (2008); available at http://www.bipm.org/utils/common/documents/jcgm/JCGM_100_2008_E.pdf (accessed Aug 2011); see also Taylor, B.N.; Kuyatt, C.E.; Guidelines for Evaluating and Expressing the Uncertainty of NIST Measurement Results; NIST Technical Note 1297; U.S. Government Printing Office: Washington, DC (1994); available at http://www.nist.gov/pml/pubs/index.cfm (accessed Aug 2011). 


\section{Appendix II. Chemical analysis}

Two un-annealed samples, one of SRM 1967a and one of SRM 1967, were analyzed for chemical impurities by a commercial testing laboratory, using glow-discharge mass spectrometry. These measurements do not have claimed traceability to NIST, and the values are not certified. Nonetheless, the measurements provide useful insight into the impurities found in both lots of platinum.

Table 1 lists the impurity concentrations as originally certified for SRM 1967 and the concentrations for both SRM 1967 and 1967a as tested in 2008. Additionally, using the coefficients either measured or calculated by Cochrane [7], we calculated the change on emf at $1200{ }^{\circ} \mathrm{C}, \Delta \operatorname{emf}\left(1200{ }^{\circ} \mathrm{C}\right)$. (We assumed that on annealing, both samples would liberate volatile gases and reach chemical equilibrium with atmospheric oxygen.)

Comparing the results from 2008 for both lots, one sees that the SRM1967a sample has less silicon and lead, but more selenium and iron. The predicted change in emf for SRM 1967 is very close for both the 1967 recommended values and the 2008 analysis, but a statistical analysis of the differences for individual elements shows that the 1967 and 2008 results differ by an rms amount of $90 \%$ for elements with a concentration of at least $0.5 \mu \mathrm{g} / \mathrm{g}$.

The accuracy of the prediction for $\Delta \operatorname{emf}\left(1200{ }^{\circ} \mathrm{C}\right)$ is difficult to determine for the following reasons:

- $\quad$ only one sample was taken for each assay;

- the analysis may be more sensitive to contaminants on the surface than in the bulk;

- the uncertainty of chemical assays is approximately $90 \%$, as discussed above;

- chemical assays cannot distinguish between electrically active and electrically neutral forms (e.g., $\mathrm{Si}$ in solution or $\mathrm{SiO}_{2}$ ); and

- the chemical composition of the wire may change upon annealing.

Given these limitations, a safe deduction from the data is that both lots of platinum have a chemical purity of approximately $99.999 \%$ by weight, and the thermoelectric emf at $1200{ }^{\circ} \mathrm{C}$ for the two lots should agree to within approximately $3 \mu \mathrm{V}$. 
Table 1. Chemical analyses of the impurity concentrations for the SRM1967 and SRM 1967a lots of platinum, and the predicted change of emf at $1200{ }^{\circ} \mathrm{C}, \Delta \mathrm{emf}$, with reference functions at $0{ }^{\circ} \mathrm{C}$. Bold font indicates the dominant impurities. A '-'indicates that no certified value was provided for that element. For the 2008 results, only elements with a concentration of at least $0.1 \mu \mathrm{g} / \mathrm{g}$ for one of the assays were listed.

\begin{tabular}{|c|c|c|c|c|c|c|c|c|}
\hline \multicolumn{5}{|c|}{1967 analysis } & \multicolumn{4}{|c|}{2008 analysis } \\
\hline & recommended & range of & & & SRN & M 1967 & SRI & M 1967a \\
\hline & concentration & meas. values & $\Delta \operatorname{emf}\left(1200^{\circ} \mathrm{C}\right)$ & & concentration & $\Delta \operatorname{emf}\left(1200^{\circ} \mathrm{C}\right)$ & concentration & $\Delta \operatorname{emf}\left(1200^{\circ} \mathrm{C}\right)$ \\
\hline & $\mu \mathrm{g} / \mathrm{g}$ & & $\mu \mathrm{V}$ & & $\mu \mathrm{g} / \mathrm{g}$ & $\mu \mathrm{V}$ & $\mu \mathrm{g} / \mathrm{g}$ & $\mu \mathrm{V}$ \\
\hline oxygen & 4 & 3.2 to 5.2 & & oxygen & & & & \\
\hline sodium & & - & & sodium & 0.18 & 0.00 & 0.20 & 0.00 \\
\hline magnesium & $<1$ & $<0.05$ to 2 & 0.11 & magnesium & 0.022 & 0.00 & 0.075 & 0.02 \\
\hline aluminum & & - & & aluminum & 0.15 & 0.09 & 0.07 & 0.04 \\
\hline silicon & & - & & silicon & 0.47 & 0.55 & 0.16 & 0.19 \\
\hline potassium & & - & & potassium & 0.27 & -0.01 & 0.27 & -0.01 \\
\hline iron & 0.7 & 0.6 to 2.6 & 1.61 & iron & 0.61 & 1.40 & 1.6 & 3.68 \\
\hline nickel & $<1$ & 0.3 to $<1$ & 0.25 & nickel & 0.17 & 0.08 & 0.055 & 0.03 \\
\hline copper & 0.1 & 0.087 to $<1$ & 0.01 & copper & 0.18 & 0.02 & 0.5 & 0.06 \\
\hline zinc & & - & & zinc & 0.07 & 0.03 & 0.12 & 0.05 \\
\hline selenium & & - & & selenium & 0.10 & 0.58 & 0.22 & 1.29 \\
\hline zirconium & $<0.1$ & $<0.03$ to 0.3 & 0.07 & zirconium & $<0.01$ & 0.01 & $<0.01$ & 0.01 \\
\hline ruthenium & & - & & ruthenium & 0.11 & 0.12 & 0.12 & 0.13 \\
\hline rhodium & $<0.2$ & 0.09 to $<1$ & 0.02 & rhodium & 0.25 & 0.05 & 1.8 & 0.36 \\
\hline palladium & 0.2 & $<0.1$ to $<1$ & 0.01 & palladium & 0.27 & 0.02 & 0.06 & 0.00 \\
\hline silver & $<0.1$ & $<0.06$ to $<1$ & 0.00 & silver & 0.016 & 0.00 & 0.18 & 0.00 \\
\hline iridium & $<0.01$ & 0.007 to 0.01 & 0.00 & iridium & 0.1 & 0.04 & 0.65 & 0.23 \\
\hline gold & $<1$ & $<0.1$ to 8 & -0.04 & gold & 1 & -0.07 & 3 & -0.21 \\
\hline lead & $<1$ & 0.6 to 3 & 1.50 & lead & 0.18 & 0.54 & 0.036 & 0.11 \\
\hline Total & & & 3.6 & Total & 4.15 & 3.5 & 9.12 & 6.0 \\
\hline
\end{tabular}

